\title{
Socioeconomic deprivation and rheumatoid disease: What lessons for the health service?
}

\author{
ERAS Study Group $\star$
}

\begin{abstract}
Objective-To assess how socioeconomic deprivation influences the presentation, treatment, and outcome of patients with rheumatoid arthritis (RA).
\end{abstract}

Methods-Three year follow up of 869 consecutive patients with RA from nine hospital rheumatology clinics, with patients categorised by the Carstairs deprivation score of their enumeration district of residence. Outcomes included Health Assessment Questionnaire (HAQ), joint and pain scores, grip strength, functional grade, radiological evidence of bony erosions, and medical/surgical interventions. Results-Patients from more deprived enumeration districts presented with more severe disease as judged by the HAQ score and joint scores. An increase from the 5th to the 95th centile of the Carstairs distribution was associated with an odds ratio of $1.87(95 \%$ confidence interval $(95 \%$ CI) 1.31 to 2.66 ) for an above-median HAQ score and 1.77 (95\% CI 1.23 to 2.54$)$ for an above-median joint score. Statistically non-significant deprivation trends were seen with erythrocyte sedimentation rate, pain score, and grip strength. By three years, despite no important differences in clinical management, socioeconomic differentials had worsened or remained unchanged such that clear deprivation trends were then seen in HAQ $(p=0.002)$ and joint scores $(p=0.001)$, in grip strength $(p=0.008)$, and in functional grade $(p=0.003)$. The association between deprivation and HAQ at three years was present after adjustment for age, sex, treatment centre, and HAQ at presentation (adjusted odds ratio $1.74,95 \%$ CI 1.1 to 2.74).

Conclusions-Socioeconomic deprivation was associated with a worse clinical course of rheumatoid disease, and this effect was already apparent at presentation, but not with systematic differentials in its treatment. This suggests that individual susceptibility and lifestyle factors contribute to socioeconomic differentials in outcome, an observation that has implications for clinical management. (Ann Rheum Dis 2000;59:794-799)

Reports from the US, ${ }^{1}$ the Netherlands, ${ }^{2}$ and the west of Scotland ${ }^{3}$ suggest that outcome in rheumatoid disease is worse in patients of lower socioeconomic status. Why is unclear, but possible explanations include delays in reaching clinical attention due to differences in thresholds for seeking medical advice or in access to health care; differences in clinical management ${ }^{4}$; variation in compliance with treatment; greater vulnerability to disease progression due to comorbidity ${ }^{15}$; and behavioural and lifestyle factors, such as smoking, diet, stress, and occupation.

Evidence about the effect of these factors in rheumatoid disease on disease development and its clinical progression is limited.$^{5-8}$ Most of the published evidence is based on cross sectional or retrospective studies of comparatively small, selective patient groups with variable disease duration. We report here an analysis of a large prospective cohort of patients enrolled in the Early Rheumatoid Arthritis Study (ERAS) that provides evidence of differentials in clinical outcome despite uniform treatment across socioeconomic groups.

\section{Methods}

ERAS was formed in 1987 with the primary aim of investigating the progress, treatment, and prognosis of patients with rheumatoid disease in routine practice. The group recruited patients at nine hospitals in England, serving populations of varied socioeconomic mix. ${ }^{9}$

Consecutive patients diagnosed as having RA by the consultant rheumatologist were recruited to the study as long as symptoms of RA had lasted for less than two years and disease modifying antirheumatic drugs (DMARDs) had not been used. Patients were excluded if the diagnosis changed-for example, apparent early RA evolving to classical lupus. Patients did not have to meet the 1987 revised American College of Rheumatology criteria, ${ }^{10}$ but whether or not they did meet these criteria was recorded. In the first year, patients were seen five times at $0,1,3,6,12$ months and at yearly intervals from then on.

\section{CLINICAL AND LABORATORY ASSESSMENTS}

Standard clinical assessments were made by trained metrologists. The features chosen when the study started in 1987 included those recommended in 1992 by the British Society of Rheumatology and Royal College of Physicians working group for specialist supervision of rheumatoid arthritis (RA). ${ }^{11} \mathrm{~A}$ doctor's and a patient's global assessment were the only two features of the core dataset recommended by the OMERACT conference in $1993^{12}$ which were not included at the start of the study. The following were included: features at onset of RA and coexistent and family medical conditions. Joint activity was scored according to both Ritchie $^{13}$ and a simple joint score, the latter allowing for both swelling without pain or tenderness, and for the number of actual joints affected to include individual
*Details of members of the study group are given in the appendix. 
metacarpophalangeal, proximal interphalangeal, and metatarsophalangeal joints ( 0 or 1 for each joint, with a maximum of 59). ${ }^{14}$ Functional grade was assessed by the clinician according to Steinbrocker (I to IV). ${ }^{15}$ All patients completed the disability index of the modified Stanford Health Assessment Questionnaire (HAQ, range $0-3) .{ }^{16}$ Early morning stiffness was recorded in hours duration and grip strength was measured in millimetres in both hands (from a resting $30 \mathrm{~mm} \mathrm{Hg}$ in a standard way). The patient marked a $100 \mathrm{~mm}$ visual analogue scale for pain experienced. Evidence of any systemic features (weight loss, fever, etc) or extra-articular signs (nodules, pulmonary fibrosis, etc) were noted. Erosive disease was assessed from standard radiographs of hands and feet performed yearly. ${ }^{17}$ Routine haematological and biochemical screen, Westergren erythrocyte sedimentation rate (ESR), and serological tests for rheumatoid factor (RF) and antinuclear antibodies were carried out.

\section{DRUG TREATMENT AND INPATIENT}

INTERVENTIONS

All centres followed the framework of the published UK guidelines for management of RA, with sequential treatment with one drug at a time the usual practice. The DMARDs used were chosen according to the doctor's preference, though dosage schedules using graduated regimens were previously agreed according to standard practice for each drug. Protocols for treatment effects had also been previously agreed and were recorded prospectively for each patient. Treatment outcome was based on continuation or not of the initial second line drug. Reasons for withdrawing drugs were based on clinical judgments and recorded prospectively as loss or lack of effect, adverse events, both reasons, remission, or miscellaneous (for example, pregnancy, lack of compliance). Clinical remission or stability while taking a specific DMARD was coded as effective. Inpatient interventions by three years were classified as rheumatological (for example, medical treatment of complications of RA or treatment), or, if orthopaedic, as minor (for example, carpal tunnel release), moderate (for example, synovectomy), or major (for example, joint replacement).

Socioeconomic status was categorised in two ways:

1 By assigning to each patient the Carstairs deprivation score of his or her enumeration district of residence (average enumeration district size approximately 140 households) identified from the patient's address postcode. The Carstairs score, ${ }^{18}$ a composite of four variables-male unemployment, social class of head of household, overcrowding, and access to a car-was computed from 1991 census small-area statistics. This index of deprivation, which has been widely used in geographical studies of health in the United Kingdom, ${ }^{19}$ is a strong predictor of health status: all causes of mortality and many cause-specific death rates, for exam-

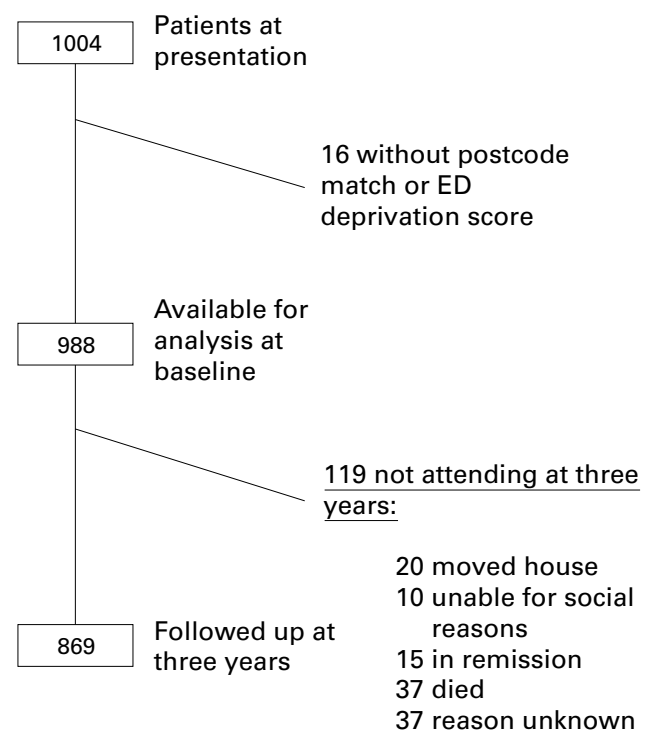

Figure 1 Patient sample. ED = enumeration district.

ple, show a greater than twofold variation across the range of Carstairs scores.

2 A subset of 685 patients from eight centres were also categorised by educational attainment (one ERAS centre did not collect this item): university/national diploma; school leavers examination at $17 / 18$ years (for example, "A" level) or vocational training; school leavers examination at 15/16 (for example, "O" level or Certificate of Secondary Education); none.

Of 1004 patients due for their three year follow up by end of 1997,988 could be matched to their enumeration district of residence and hence categorised for deprivation. One hundred and nineteen (12.0\% of the 988) were not followed up at three years for reasons shown in fig 1 , so that 869 patients form the basis of this report.

\section{STATISTICAL METHODS}

The association between socioeconomic status and clinical variables was examined by tabulation and regression methods. Numerical variables are shown as medians and interquartile ranges and categorical variables as numbers and percentages.

Most variables had highly asymmetrical distributions and both trend tests and multivariate analyses were based on ordinal logistic modelling. ${ }^{20}$ In each case the dependent variable was categorised into quartiles. Odds ratios from ordinal logistic regression can be interpreted similarly to those of a conventional logistic model; here they can be thought of as the odds ratios of having a score above the median of the dependent variable in question. All odds ratios are presented as the ratio for an increase from the 5 th to the 95 th centile of the Carstairs distribution. Analyses of drug treatment (classified as low dose steroids or non-steroidal anti-inflammatory drugs only; second line treatment; complex treatment) and of inpatient treatment (classified as outpatient only; medical inpatient treatment only; and surgical intervention) were analysed by multinomial logistic modelling. 
Table 1 Clinical characteristics and their variation by Carstairs score

\begin{tabular}{|c|c|c|c|c|c|c|c|c|}
\hline \multirow[b]{2}{*}{ Characteristic } & \multirow[b]{2}{*}{$n$} & \multirow{2}{*}{$\begin{array}{l}\text { Median (interquartile } \\
\text { range) or count } \\
\text { (percentage) }\end{array}$} & \multicolumn{4}{|c|}{ Percentage above median or positive for characteristic } & \multirow[b]{2}{*}{$\begin{array}{l}\text { Unadjusted odds ratio } \\
(95 \% \mathrm{CI}) t\end{array}$} & \multirow[b]{2}{*}{$\begin{array}{l}p \text { Value for } \\
\text { trend }\end{array}$} \\
\hline & & & $\begin{array}{l}Q 1^{\star} \\
(n=252)\end{array}$ & $\underset{(n=242)}{Q 2}$ & $\underset{(n=247)}{Q 3}$ & $\underset{(n=247)}{Q 4}$ & & \\
\hline Age (years) & 988 & $56(44-65)$ & 49.2 & 43.8 & 48.2 & 48.6 & $0.94(0.66$ to 1.33$)$ & $>0.2$ \\
\hline Female (\%) & 988 & $643(65.1)$ & 62.7 & 65.3 & 66.4 & 67.0 & $0.97(0.64$ to 1.46$)$ & $>0.2$ \\
\hline Symptom duration (months) & 988 & $6(4-11.5)$ & 52.0 & 45.5 & 51.0 & 48.2 & $0.68(0.48$ to 0.97$)$ & 0.16 \\
\hline \multicolumn{9}{|c|}{ Clinical markers at presentation visit } \\
\hline RF positive (\%) & 984 & $615(62.5)$ & 64.5 & 64.1 & 59.4 & 62.0 & $0.77(0.52$ to 1.15$)$ & 0.17 \\
\hline$x$ Ray erosions $(\%)$ & 859 & $245(28.5)$ & 24.1 & 23.3 & 25.7 & 28.9 & $1.37(0.88$ to 2.12$)$ & 0.15 \\
\hline HAQ & 983 & $1(0.5-1.625)$ & 40.9 & 42.7 & 49.2 & 52.9 & $1.87(1.31$ to 2.66$)$ & 0.001 \\
\hline ESR & $852 \ddagger$ & $34(17-58)$ & 47.0 & 46.2 & 49.3 & 53.4 & $1.29(0.84$ to 1.98$)$ & $>0.2$ \\
\hline Joint score & 985 & $14(7-25)$ & 46.8 & 44.4 & 50.0 & 54.1 & $1.77(1.23$ to 2.54$)$ & 0.002 \\
\hline Pain score & 953 & $41(22-61)$ & 45.6 & 50.8 & 49.6 & 52.8 & $1.08(0.75$ to 1.54$)$ & $>0.2$ \\
\hline Grip strength & 983 & $140(95-210)$ & 52.0 & 52.3 & 46.9 & 43.3 & $0.74(0.52$ to 1.05$)$ & 0.09 \\
\hline \multicolumn{9}{|l|}{ Clinical markers at three years } \\
\hline HAQ & 831 & $0.75(0.25-1.375)$ & 41.0 & 50.5 & 49.5 & 50.0 & $1.82(1.24$ to 2.67$)$ & 0.002 \\
\hline ESR & $703+$ & $20(10-41)$ & 43.2 & 48.4 & 51.4 & 51.1 & $1.27(0.80$ to 2.02$)$ & $>0.2$ \\
\hline Joint score & 828 & $7(2-16.5)$ & 36.9 & 49.0 & 51.2 & 57.1 & $1.91(1.28$ to 2.86$)$ & 0.001 \\
\hline Pain score & 822 & $27(7-50)$ & 45.8 & 54.2 & 43.6 & 52.8 & $1.12(0.76$ to 1.64$)$ & $>0.2$ \\
\hline Grip strength & 832 & $170(115-260)$ & 59.4 & 49.5 & 42.9 & 43.4 & $0.60(0.41$ to 0.88$)$ & 0.008 \\
\hline Function grade II-IV (\%) & 838 & $444(53.0)$ & 42.4 & 53.4 & 55.1 & 61.7 & $1.95(1.25$ to 3.02$)$ & 0.003 \\
\hline Died $(\%)$ & & $37(3.7)$ & 2.6 & 4.9 & 4.2 & 4.2 & $1.4(0.55$ to 3.6$)$ & $>0.2$ \\
\hline \multicolumn{9}{|c|}{ Change in clinical markers, presentation to three years } \\
\hline HAQ & 829 & $-0.125(-0.63-0.25)$ & 43.3 & 49.3 & 43.4 & 45.6 & $0.90(0.62$ to 1.32$)$ & $>0.2$ \\
\hline ESR & $702 \ddagger$ & $-8(-26-3)$ & 45.2 & 51.6 & 53.7 & 45.8 & $0.87(0.55$ to 1.37$)$ & $>0.2$ \\
\hline Joint score & $826^{\circ}$ & $-5(-14-2)$ & 43.9 & 53.2 & 48.5 & 42.9 & $0.87(0.60$ to 1.27$)$ & $>0.2$ \\
\hline Pain score & 795 & $-10(-32-8)$ & 50.0 & 50.0 & 40.2 & 50.3 & $1.05(0.71$ to 1.56$)$ & $>0.2$ \\
\hline Grip strength & 820 & $20(-20-70)$ & 52.3 & 43.4 & 47.3 & 48.5 & $1.02(0.70$ to 1.49$)$ & $>0.2$ \\
\hline
\end{tabular}

${ }^{\star}$ Quartile of the Carstairs distribution: Q1 least deprived, Q4 most deprived.

†Odds ratio associated with an increase from the 5 th to the 95 th centile of the Carstairs score.

$\ddagger$ Viscosity and not ESR was recorded at one centre.

$\uparrow \mathrm{RF}=$ rheumatoid factor; HAQ = Health Assessment Questionnaire; ESR = erythrocyte sedimentation rate.

\section{Results}

At presentation, there was little variation across the deprivation groups in age, sex, duration of symptoms, the proportion of patients positive for $\mathrm{RF}$, or in the proportion with bony erosions (table 1). There was, however, strong evidence of a positive deprivation trend with HAQ score and joint score, and weaker evidence of a negative trend with grip strength. ESR and pain scores were fairly constant across deprivation groups, and the trends were statistically non-significant at the 5\% level. In England and Wales the proportions of enumeration districts in these quartiles are $20.4 \%$ (least deprived quartile, Q1), $17.7 \%, 19.8 \%$, and $42.0 \%$. Thus the ERAS study group was somewhat less deprived than the national average.

The mode of treatment was fairly consistent across the deprivation groups (table 2), including use of low dose steroids alone (8-10\%). The unadjusted analysis provided evidence of a trend of more complex drug treatment (that is, second line drug combinations after loss of effect of the first or second disease modifying drug) in patients from more deprived areas, but the significance was lost $(\mathrm{p}=0.18)$ after adjustment for age, sex, and treatment centre. The trend of more inpatient medical treatment in

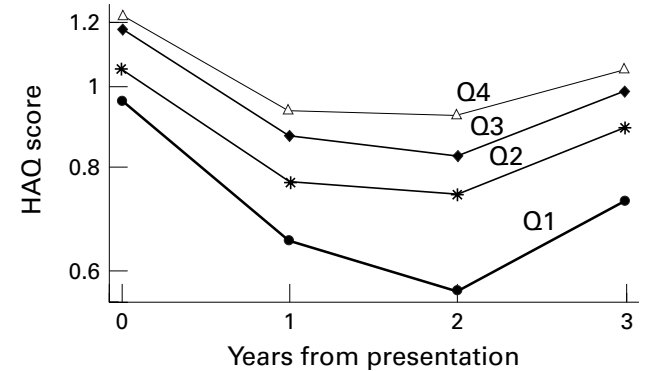

Figure 2 Change in mean Health Assessment Questionnaire (HAQ) score (log scale) by quartile (Q1 least deprived, Q4 most deprived) of the Carstairs deprivation score.

patients from more deprived enumeration districts was also lost after similar adjustment $(\mathrm{p}>0.2)$.

By three years, each of the main clinical markers (HAQ, ESR, joint score, pain score, grip strength) had improved (changes in HAQ shown in fig 2), though the socioeconomic differentials seen at presentation remained or were accentuated: statistically significant positive trends were seen between deprivation and functional grade, HAQ, and joint scores, and a negative association was seen with grip strength. As before, $x$ ray erosions, ESR, and

Table 2 Treatment by quartile of Carstairs score. Results are shown as number (\%)

\begin{tabular}{|c|c|c|c|c|c|}
\hline & \multicolumn{4}{|c|}{ Carstairs deprivation quartile } & \multirow{2}{*}{$\begin{array}{l}p \text { Value for } \\
\text { trend }\end{array}$} \\
\hline & 1 (least deprived) & 2 & 3 & 4 (most deprived) & \\
\hline \multicolumn{6}{|l|}{ Drug treatment } \\
\hline Steroids or NSAIDs ${ }^{\star}$ only & $51(23)$ & $34(16)$ & $43(20)$ & $39(18)$ & \\
\hline Second line treatment & $136(62)$ & $144(68)$ & $120(57)$ & $119(56)$ & $>0.2$ \\
\hline Complex & $34(15)$ & $33(16)$ & $48(23)$ & $54(25)$ & 0.02 \\
\hline \multicolumn{6}{|l|}{ Inpatient treatment } \\
\hline None & $173(77)$ & $152(72)$ & $146(68)$ & $140(65)$ & \\
\hline Medical only & $37(17)$ & $48(23)$ & $47(22)$ & $61(28)$ & 0.01 \\
\hline Surgery & $14(6)$ & $12(6)$ & $21(10)$ & $16(7)$ & 0.28 \\
\hline
\end{tabular}

^NSAIDs = non-steroidal anti-inflammatory drugs. 
Table 3 Ordinal logistic model: odds ratio of a Health Assessment Questionnaire score greater than 0.75 (that is, median) at three years

\begin{tabular}{|c|c|c|c|c|}
\hline & Odds ratio $(95 \%$ CI) & Likelihood $\chi^{2}$ & $d f$ & $p$ Value \\
\hline Carstairs deprivation score ${ }^{\star}$ & $1.74(1.10$ to 2.74$)$ & 5.76 & 1 & 0.02 \\
\hline \multicolumn{5}{|l|}{ Age group (years): } \\
\hline-44 & 1 & & & \\
\hline 45 to 54 & 1.71 (1.18 to 2.47$)$ & 10.1 & 3 & 0.02 \\
\hline 55 to 64 & $1.41(0.98$ to 2.02$)$ & & & \\
\hline $65+$ & $1.68(1.15$ to 2.45$)$ & & & \\
\hline \multicolumn{5}{|c|}{ 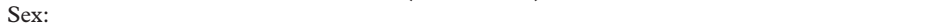 } \\
\hline Male & 1 & 24.0 & 1 & $<0.001$ \\
\hline Female & $2.01(1.52$ to 2.66$)$ & & & \\
\hline Centre & - & 9.51 & 8 & 0.30 \\
\hline \multicolumn{5}{|l|}{ HAQ score at presentation: } \\
\hline Quartile 1 & 1 & & & \\
\hline Quartile 2 & $1.61(1.14$ to 2.30$)$ & 121.4 & 3 & $<0.001$ \\
\hline Quartile 3 & $4.10(2.83$ to 5.95$)$ & & & \\
\hline Quartile 4 & $7.66(5.08-11.6)$ & & & \\
\hline
\end{tabular}

${ }^{\star}$ Odds ratio corresponding to an increase from the 5 th to the 95 th centile of the Carstairs score.

pain score showed no statistically significant association (trends non-significant at the 5\% level). The change between presentation and three years in HAQ score, ESR, joint and pain scores, and grip strength did not vary appreciably with deprivation, and in no case was the pattern or statistical test strongly suggestive of a trend.

Table 3 shows the results of the multivariable analyses. The probability of having an HAQ score above the median at three years was greater in women than men and greater in those aged 45 years or more compared with younger patients. The probability was also substantially greater in those with high HAQ scores at presentation. After adjusting for these factors and for the treating hospital, an increase from the 5 th to the 95 th centile of the deprivation distribution was associated with an odds ratio of 1.74 (95\% CI 1.10 to 2.74$)$. Thus patients from more deprived enumeration districts were at greater risk of a high HAQ score at three years after allowing for their higher initial scores - that is, they showed less improvement over time.

EDUCATIONAL ATTAINMENT

Table 4 shows the tabulation of markers of disease by educational attainment. Clear age and sex differences were seen, reflecting the strong cohort effect in educational attainment; patients who reached university/national diploma were relatively younger, and relatively fewer were women.
After adjusting for age and sex, there was evidence that $\mathrm{HAQ}$, pain scores, and grip strength at presentation were related to educational attainment, but the ESR and joint scores were not. At three years all these clinical markers, except ESR, showed evidence of trends with educational attainment, with the more highly educated patients having more favourable scores.

The above analyses of clinical progress in relation to enumeration district Carstairs score and educational attainment were repeated for the subset of 818 patients meeting the ACR criteria. Results for this subgroup differed in only minor respects and, therefore, are not separately reported.

PATIENTS LOST TO FOLLOW UP

Figure 1 gives the reasons why patients did not complete three years' follow up. Thus, from the original cohort, only 37/988 (3.7\%) were unaccounted for, 15 (1.5\%) opted to discontinue because of clinical remission, and 37 $(3.7 \%)$ had died. These patients were analysed separately. Not surprisingly in the patients who died, the median age was higher (69 years $v 55$ years, $p<0.0001$ ) and the proportion of men to women was higher (45:55 v 35:65, not significant). Most of the clinical and laboratory variables at presentation were worse in this group - for example, median HAQ $1.5 v 1.0$ $(\mathrm{p}=0.0007)$, and ESR 54 v $33(\mathrm{p}=0.007)$. Although there was a trend for a lower socioeconomic environment in these patients, this did not reach significance.

\section{Discussion}

There is no evidence that the development of RA is affected by socioeconomic status, ${ }^{7}$ but it is clear from our results that the effect of deprivation is apparent at first presentation, and that older women from a lower socioeconomic environment and with an initially worse HAQ did not follow the overall trend for improvement in function.

Functional ability is considered an important measure of clinical status of RA and outcome, and the HAQ a valuable and widely used tool for this. ${ }^{16}$ The HAQ has been reported to be the most representative of all

Table 4 Patient characteristics and clinical markers by educational attainment

\begin{tabular}{|c|c|c|c|c|c|c|c|}
\hline & \multirow[b]{2}{*}{$n$} & \multirow[b]{2}{*}{$\begin{array}{l}\text { Median (interquartile } \\
\text { range) or count } \\
\text { (percentage) }\end{array}$} & \multicolumn{4}{|c|}{ Percentage above median or positive for characteristic } & \multirow[b]{2}{*}{$\begin{array}{l}p \text { Value for trend } \\
\text { (age and sex } \\
\text { adjusted analysis) }\end{array}$} \\
\hline & & & $\begin{array}{l}\text { University/ } \\
\text { National } \\
\text { diploma }(n=74)\end{array}$ & $\begin{array}{l}\text { "A"levell } \\
\text { vocational } \\
\text { training }(n=210)\end{array}$ & $\begin{array}{l}\text { “O”level/CSE } \\
(n=127)\end{array}$ & $\begin{array}{l}\text { None/no CSEs } \\
(n=274)\end{array}$ & \\
\hline Age (years) & 685 & $56(44-65)$ & 29.7 & 42.4 & 33.9 & 52.2 & - \\
\hline Female $(\%)$ & 685 & $442(64.5)$ & 47.3 & 54.8 & 82.7 & 68.3 & - \\
\hline \multicolumn{8}{|c|}{ Clinical markers at presentation visit } \\
\hline $\mathrm{HAQ}^{\star}$ & 685 & $0.5(0.125-1.625)$ & 29.7 & 39.1 & 44.1 & 53.7 & 0.002 \\
\hline $\mathrm{ESR}^{\star}$ & 572 & $34(17-58)$ & 45.1 & 49.7 & 44.7 & 47.6 & $>0.2$ \\
\hline Joint score & 684 & $14(7-25)$ & 40.5 & 47.1 & 33.9 & 55.3 & 0.13 \\
\hline Pain score & 660 & $41(22-61)$ & 40.3 & 45.4 & 50.4 & 54.9 & 0.04 \\
\hline Grip strength & 684 & $140(95-210)$ & 64.4 & 54.3 & 44.9 & 43.1 & 0.06 \\
\hline \multicolumn{8}{|c|}{ Clinical markers at three years } \\
\hline HAQ & 649 & $0.75(0.25-1.375)$ & 35.2 & 40.3 & 53.7 & 53.5 & 0.002 \\
\hline ESR & 535 & $20(10-41)$ & 48.5 & 40.4 & 56.9 & 50.5 & $>0.2$ \\
\hline Joint score & 646 & $7(2-16.5)$ & 26.8 & 45.3 & 43.0 & 51.4 & 0.006 \\
\hline Pain score & 644 & $27(7-50)$ & 40.9 & 46.2 & 58.5 & 54.7 & 0.006 \\
\hline Grip strength & 648 & $170(115-260)$ & 65.2 & 53.2 & 39.7 & 42.8 & 0.003 \\
\hline
\end{tabular}

${ }^{\star} \mathrm{HAQ}=$ Health Assessment Questionnaire; ESR = erythrocyte sedimentation rate. 
variables in depicting clinical status in $\mathrm{RA},{ }^{21}$ and is the health status measure most commonly used by rheumatologists in the UK at present. ${ }^{22}$ In a recent review of prognostic factors in RA the HAQ has been shown to have predictive qualities for morbidity, mortality, and functional outcome in a number of reports. ${ }^{23}$ This makes the findings of this study relevant to clinicians and patients for management and prognosis. The HAQ is a measure of patients' perspective of disease and reflects the true needs of patient care. It does not have a psychological component and any possible effect of anxiety or depression on function cannot be included in our analysis. None the less, it is important to detect early loss of function so that coping measures can be introduced without delay and support provided by physiotherapy and occupational therapy departments, and disease modifying drugs given early consideration. ${ }^{24}{ }^{25}$ Older women of lower socioeconomic status with worse HAQ at presentation could be identified early on.

Evidence from this study suggests that socioeconomic differentials in disease status at presentation were apparent in other more objective markers of joint disease (for example, swollen joints). Possible explanations are that patients from more deprived enumeration districts had higher thresholds for consultation or that they were more prone to the effects of rheumatoid disease. There was, however, no evidence of longer duration of symptoms before attending hospital in these patients, though the measure of disease duration depended on patient recall and may be imprecise. It is not possible from our study to know whether patients with milder onset RA in deprived areas are less likely to seek medical advice, whereas patients from privileged environments more likely to do so, and whether perceptions of disease onset and severity vary according to educational background.

Whether measured by income, occupation, educational level, or social class, poor socioeconomic environments have been shown to affect outcome adversely in many chronic disorders and have important implications for healthcare strategies. ${ }^{26}$ The conclusion of a summary of the current position in the UK was that most inequalities in health are not inevitable and are remedial. ${ }^{27}$ Educational status was first described as an important predictor of outcome in RA in cross sectional studies from the US, ${ }^{18}$ and confirmed in two small prospective studies in Europe. ${ }^{28}{ }^{29}$ The strength and significance of this association vary, probably because of differences in ascertainment of the different educational systems in these countries. In view of the effect of age on educational attainment in the UK, enumeration district based on postal code may be a more reliable index of socioeconomic status, and a study using this method in patients with RA entered into clinical trials in western Scotland found similar results. ${ }^{3}$ This group have also reported a link between premature mortality and social deprivation. ${ }^{30}$ We found little evidence of this, but over the three year follow up only 37 deaths occurred. Secure conclusions about a deprivation link will be possible from our cohort only after further follow up.

The wide variation in the severity of functional outcome in studies of RA progression is, at least in part, due to study design (especially patient selection) and limited numbers. ${ }^{23}$ The design of ERAS was intended to overcome some of these problems, and has recruited patients from various socioeconomic and geographical areas. In the first few years of RA clinical, functional, and laboratory measures improved overall. There are few reliable and consistent clinical or laboratory features which predict those who do badly in this time, but female sex, acute phase (ESR, C reactive protein) and RF have all been shown to predict a variety of outcomes. However, these features do not always hold for function, and there has been much less consistency in predicting functional outcome than radiological damage. ${ }^{23}$ The most reliable measure at the early stages of RA for predicting eventual functional outcome is functional ability at presentation, ${ }^{23}$ but the clinical use of this finding has been little explored. The evidence from our study suggests that disease progression over the first three years from presentation was worse in patients of greater socioeconomic deprivation, even after allowing for their poorer initial HAQ scores. Thus not only did they present with more severe disease as measured by the HAQ but they also did not improve as much as patients of equivalent initial HAQ scores from areas of less socioeconomic deprivation. Women and older patients also fared badly. There was some evidence of differences in treatments received (antirheumatic drugs and inpatient interventions) by socioeconomic status, but this was largely attributable to differing practices at the nine contributing centres in this study; and adjustment for centre removed evidence of an association. Although predictive factors have a number of uses, the most important one for clinicians is as a guide to treatment and early management strategies. Socioeconomic factors may have a place in the currently rather limited number of reliable prognostic factors in early RA.

Potential sources of bias in this study arise from selective referral and losses to follow up. There were neither appreciable differences in clinical or laboratory variables at presentation between those who attended at three years and those who were lost to follow up, nor any clear socioeconomic trends, except in those patients who died, and in this group, the higher proportion of older and male patients with worse function was not surprising. The nature of selection of our patients and the smaller percentage of patients who were lost to follow up favour less bias or cohort effects. The observed/expected ratio for survival was similar to a comparable study, ${ }^{31}$ and exclusion from the main analysis of the patients who died would, if anything, underestimate the extent of deprivation on disease severity.

A few studies have reported a link between socioeconomic status and severity of RA, ${ }^{1-3}$ and while the development of RA may itself 
contribute to worse socioeconomic status, our study is the first to show that this effect is already apparent at presentation (at a median of six months from onset of symptoms). Further research is required to establish the relevance of other factors which contribute to greater deprivation-for example comorbidity, diet, smoking, and which of these factors can be most easily improved. In recent years greater emphasis has been towards psychosocial explanations of socioeconomic inequalities and the concept of low perceived control. ${ }^{32}{ }^{33}$ The early HAQ changes found in our study raise the possibility of a positive discrimination programme for patients disadvantaged in this way. At present there is no provision for allocating funding in rheumatology nationally for those most in need, but at least rheumatologists and primary care doctors need to be aware of the factors likely to be associated with poor functioning at the early stages of RA, when intervention is most likely to benefit the patient. This study suggests that age, sex, HAQ, and the Carstairs deprivation score are useful for risk stratification, helping to identify patients with RA who may need more intensive drug treatment and other interventions at an early stage.

The ERAS Group is supported by an Arthritis Research Campaign (ARC) Academic Secretary Grant (ASG). This ERAS project has been supported by project grants from the ARC, the
BUPA Foundation, and Pharmacia-Upjohn. We are grateful to BUPA Foundation, and Pharmacia-Upjohn. We are grateful to
Ben Armstrong for his advice on statistical analysis and Ben Armstrong for his advice on statistical analysis and
commenting on drafts of this paper, Cathy Mayes for coordinating this project, and all ERAS centre metrologists.

\section{Appendix: members of the ERAS Study Group}

A Young, consultant rheumatologist, City Hospital, St Albans AL3 5PN, Herts, UK

$\mathrm{P}$ Wilkinson, senior lecturer, London School of Hygiene and Tropical Medicine, London WC1E 7HT, UK

J Talamo, public health assistant

J Dixey, consultant rheumatologist, Robert Jones and Agnes Hunt, Orthopaedic Hospital, Oswestry, UK

N Cox, consultant rheumatologist, Royal Hants County Hospital, Winchester SO22 5DG, UK

P Davies, consultant rheumatologist, Broomfield Hospital, Chelmsford CM1 6ET, UK

J Devlin, consultant rheumatologist, Pinderfield General Hospital, Wakefield WF1 4DG, UK

P Emery, professor of rheumatology, Rheumatology Research Unit, Leeds LS2 9NZ, UK

A Gough, consultant rheumatologist, Harrogate Hospital, Harrogate HG2 7SX, UK

D James, consultant rheumatologist, Diana Princess of Wales Hospital, Grimsby DN33 2BA, UK

P Prouse, consultant rheumatologist, North Hampshire Hospital, Basingstoke RG24 9NA, UK

P Williams, consultant rheumatologist, Medway Hospital, Gillingham ME7 5NY, UK

J Winfield, consultant rheumatologist, Royal Hallamshire Hospital, Sheffield S10 6JF, UK

1 Mitchell JM, Burkhauser RV, Pincus T. The importance of age, education, and co-morbidity in the substantial earnings losses of individuals with symmetric polyarthritis. Arthrits Rheum 1988;31:348.

2 Vliet Vlieland TPM, Buitenhuies NA, van-Zeben D, Vandenbroucke JP, Breedveld FC, Hazes JM. Sociodemographic factors and the outcome of rheumatoid arthritis in young women. Ann Rheum Dis 1994;53; 803-6.
3 McEntegart A, Morrison E, Capell HA, Duncan MR, Porter D, Madhok R, et al. Effect of social deprivation on disease severity and outcome in patients with rheumatoid ease severity and outcome in patients with

4 Criswell L. Relationship of educational level to treatment received for rheumatoid arthritis. J Rheumatol 1994;21; 2026-33

5 Talamo J, Frater A, Gallivan S, Young A. Use of short form 36 (SF36) for health status in rheumatoid arthritis. Br J Rheumatol 1997;36:463-9.

6 Berkanovic E, Oster P, Wong W, Bulpitt K, Clements P, Sterz $M$, et al. The relationship between socio-economic status and recently diagnosed rheumatoid arthritis. Arthritis Care Research 1996;9:257-62.

7 Bankhead C, Silman A, Barrett B, Scott D, Symmons D. Incidence of rheumatoid arthritis is not related to indicators of socio-economic deprivation. J Rheumatol 1996;23;2039-42.

8 Leigh JP, Fries JF. Predictors of disability in a longitudinal sample of patients with rheumatoid arthritis. Ann Rheum Dis 1992;51:581-7.

9 Young A. Short term outcomes in recent onset rheumatoid arthritis. Br J Rheumatol 1995;34(suppl 2):79-86.

10 Arnett FC, Edworthy SM, Bloch DA McShane DJ, Fries JF, Cooper NS, et al. The American Rheumatism Association 1987 revised criteria for classification of rheumatoid arthritis. Arthritis Rheum 1988;31:315-24.

11 Joint working group of British Society of Rheumatology and Royal College of Physicians. Guidelines and audit measures for the specialist supervision of patients with rheumatoid arthritis. J R Coll Physicians Lond 1992;26:76-82.

12 Tugwell P, Boers M. Proceedings of OMERACT conference on outcome measures in rheumatoid arthritis in clinical trials. J Rheumatol 1993;20:528-30

13 Ritchie DM, Boyle JA, McInnes JM, Jasani MK, Dalakos TG, Grieveson P, et al. Clinical studies with an articular index for the assessment of joint tenderness in patients with rheumatoid arthritis. Q J Med 1968;147:393-406.

14 Young A, Corbett $M$, Winfield J, Jaqueremada D, Williams $\mathrm{P}$, Papasavvas G, et al. A prognostic index for erosive changes in the hands, feet, and cervical spines in early heumatoid arthritis. Br J Rheumatol 1988;27:94-101.

15 Steinbrocker O, Traeger CH, Batterman RC. Therapeutic criteria in rheumatoid arthritis. JAMA 1949;140:659-62.

6 Fries J, Spitz P, Young D. Dimensions of health outcomes: the health assessment questionnaire, disability and pain scales. J Rheumatol 1982;9:789-93.

17 Lawrence JS. Radiological classification. In: Rheumatism in populations. London:Heinmann, 1977.

18 Carstairs V, Morris R. Deprivation and health in Scotland. Aberdeen: Aberdeen University Press, 1991

19 Carstairs V. Deprivation indices: their interpretation and use in relation to health. J Epidemiol Community Health 1995;49(suppl 2):S3-8.

20 Armstrong B, Sloan M. Ordinal regression methods for epidemiologic data. Am J Epidemiol 1989;129:191-204.

21 Pincus T, Callahan LF, Vaughan WK. Questionnaire, walking time and button test measures of functional capacity as predictive markers for mortality in rheumatoid arthritis. J Rheumatol 1987;14:240-5.

22 Carr A, Thompson P, Young A. Do health status measures (HSM) have a role in rheumatology? A survey of the use of and attitudes towards health status measures in the UK [abstract]. Arthritis Rheum 1996;9(suppl):S261.

23 Young A, van der Heijde D. Can we predict aggressive disease? Clin Rheumatol 1997;11:27-48

24 van der Heide A, Jacobs JWG, Bijlsma JWJ, Heurkens AH, van-Booma-Franfort C, van-der-Veen MJ, et al. The effectiveness of early treatment with "second line" antirheumatic drugs. Ann Intern Med 1996;124:699-707.

25 Allander E, Lundt B, Borge G, Allander E, Lind B, Berg E, et al. Auranofin improves outcome in early rheumatoid et al. Auranofin improves outcome in

26 Marmot MG, McDowall ME. Mortality decline and widening social inequalities. Lancet 1986;i:274-6.

27 Acheson D. Equality of health: dream or reality? J R Col Physicians Lond 1999;33:70-7

28 van Leeuwen, MA, van der Heijde $\mathrm{D}$, van Rijswijk $\mathrm{MH}$, Houtman PM, van-Riel PL van de Putte LB, et al. Interrelationship of outcome measures and process variables in early rheumatoid arthritis. J Rheumatol 1994;21:3 425

29 Eberhardt KB, Fex E. Functional impairment and disability in early rheumatoid arthritis -development over 5 years. J Rheumatol 1995;22:1037-42.

30 Madhok R, Maiden N, Capell HA, Thomson EA. Does social disadvantage contribute to the excess mortality in rheumatoid arthritis patients? Ann Rheum Dis 1999;58: 525-9.

31 Corbett M, Dalton D, Young A, Silman A, Shipley M, et al. Factors predicting death, survival and functional outcome in a prospective study of early rheumatoid disease over fifteen years. Br J Rheumatol 1993;32:717-23.

32 Marmot MG, Bosma H, Hemingway H, Brunner E, Stansfeld S. Contribution of job control and other risk factors to social variations in coronary heart disease incidence. Lancet 1997;349:235-9.

33 Bosma H, Schrijvers C, Mackenbach JP. Socio-economic inequalities in mortality and importance of perceived control: cohort study. BMJ 1999;319:1469-70. 